\section{(6) OPEN ACCESS}

${ }^{1}$ Health Promotion Section, Graduate School of Tokyo Medical and Dental University, Tokyo, Japan

${ }^{2}$ School of Nursing, Muhimbili University of Health and Allied Sciences, Dar es Salaam, Tanzania

${ }^{3}$ Department of Nursing, School of Health Sciences, Nagasaki University, Nagasaki, Japan

${ }^{4}$ International Health Section, Graduate School of Tokyo Medical and Dental University, Tokyo, Japan

\section{Correspondence to} Dr Takehito Takano, Health Promotion Section, Graduate School of Tokyo Medical and Dental University, Yushima 1-5-45, Bunkyo-ku, Tokyo 113-8510, Japan; whocc.hlth@tmd.ac.jp

Received 31 May 2012 Revised 9 November 2012 Accepted 27 November 2012 Published Online First 15 January 2013

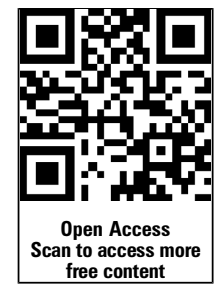

To cite: Kibusi SM, Ohnishi M, Outwater A, et al. Inj Prev 2013;19: 320-325.

\title{
Sociocultural factors that reduce risks of homicide in Dar es Salaam: a case control study
}

\author{
Stephen Matthew Kibusi, ${ }^{1,2}$ Mayumi Ohnishi, ${ }^{3}$ Anne Outwater, ${ }^{2}$ Kaoruko Seino, ${ }^{4}$ \\ Masashi Kizuki, ${ }^{1}$ Takehito Takano ${ }^{1}$
}

\section{ABSTRACT \\ Objectives This study was performed to examine the potential contributions of sociocultural activities to reduce risks of death by homicide.}

Methods This study was designed as a case control study. Relatives of 90 adult homicide victims in Dar es Salaam Region, Tanzania, in 2005 were interviewed. As controls, 211 participants matched for sex and 5-year age group were randomly selected from the same region and interviewed regarding the same contents.

Results Bivariate analysis revealed significant differences between victims and controls regarding educational status, occupation, family structure, frequent heavy drinking, hard drug use and religious attendance. Conditional logistic regression analysis indicated that the following factors were significantly related to not becoming victims of homicide: being in employment (unskilled labour: $\mathrm{OR}=0.04$, skilled labour: $\mathrm{OR}=0.07$, others: $O R=0.04)$, higher educational status $(O R=0.02)$, residence in Dar es Salaam after becoming an adult (compared with those who have resided in Dar es Salaam since birth: $O R=3.95$ ), living with another person $(O R=0.07)$, not drinking alcohol frequently $(O R=0.15)$ and frequent religious service attendance $(\mathrm{OR}=0.12)$.

Conclusions Frequent religious service attendance, living in the same place for a long time and living with another person were shown to be factors that contribute to preventing death by homicide, regardless of place of residence and neighbourhood environment. Existing nonstructural community resources and social cohesive networks strengthen individual and community resilience against violence.

\section{INTRODUCTION}

Over the past two decades, violence in the form of suicide, homicide and war has remained one of the leading causes of death worldwide. The WHO estimated 535000 deaths due to violence occurred in the world in 2008. ${ }^{1}$ Interpersonal violence was the second leading cause of injury deaths among men aged 15-44 years in 2008, after road traffic injuries. ${ }^{1}$ WHO reported homicide death rate was nearly three times greater than suicide rate among deaths caused by violence in the African region, and this differs from the European, Southeast Asian and western Pacific regions. ${ }^{2}$

Homicide rates in Tanzania for males being 22.3 per 100000 population and for females being 2.6 per 100000 population, continues to be higher than the world average of 8.8 per 100000 population. ${ }^{3}$ The average of the national homicide rate in 2007 was 9.0 per 100000 population, ${ }^{4}$ and the rate of homicide deaths in the Dar es Salaam region, Tanzania was 12.6 per 100000 population in $2005 .^{5}$

Homicide rates tend to be higher in urban settings. ${ }^{6}$ Higher homicide rates have been reported in urban as compared with rural wards of the Dar es Salaam region, Tanzania. ${ }^{5}$ Dar es Salaam has one of the highest crime rates in Tanzania, accounting for up to $26.0 \%$ of all crimes reported to the police throughout the country in 1996 . $^{7}$

The rate of homicide death is greater among men than women. ${ }^{1}$ Lower educational level ${ }^{8}$ and unstable employment ${ }^{9}$ are risk factors against homicide deaths. Living alone, singlehood and social isolation increase the probability of becoming a victim of homicide. ${ }^{10}$ Alcohol consumption ${ }^{11}$ and drug use $^{12}$ were reported to be directly associated with fatal injuries, premature unnatural deaths and homicide deaths.

Studies showed that adherence to traditional social and religious values and activities acted to protect from violence and crime. ${ }^{13}{ }^{14}$ Low religious observance, peer delinquency, low perceived likelihood of being caught and high neighbourhood disorder/crime were risk factors of violence among teenagers. ${ }^{13}$ Religiosity measured as the frequency of attendance to religious services was reported to protect youths from drug use, fighting and theft behaviour. ${ }^{14}$ The lack of social capital was associated with physical fights among young men in Beirut. ${ }^{15}$ A comprehensive tool was employed in the current study to measure the relationship of these factors with homicide in the context of a low resource setting.

Homicide includes assault and mob violence. The latter is defined as the spontaneous or planned killing of an individual or a small group by a medium to large group of people. Among homicide deaths in Tanzania, 57\% were due to mob violence or acts of collective violence, ${ }^{5}$ which is exceptionally high compared with many other countries in the world. Unemployment and economic inequalities, especially among young people, were reported as the major reasons driving people to rob and consequently leading them to becoming victims of mob violence. ${ }^{5}$

A study in South Africa reported that the social dynamics that support violence were widespread poverty, unemployment and income inequality. ${ }^{16}$ Countries with lower per capita income have higher homicide rates, especially in Africa and the Americas than in other regions. ${ }^{17}$ However, most of the studies on risk factors of homicide were conducted in high-income countries or middle-income countries (low income $\leq \$ 1005$; lower-middle income, \$1006-\$3975; upper-middle income, 
$\$ 3976$-\$12 275; and high income, $\geq \$ 12276$, according to the Gross National Product (GNP) per capita reported by World Bank, 2012).

Little attention has been paid in developing countries to the study of the individual and family risk factors for violence. ${ }^{2}$ Efforts should be made to examine why some families and individuals in Africa with diverse ethnicity remain protected against homicide, despite poverty, lack of education, unemployment and lack of opportunities, whereas others experience enduring patterns of violence.

Tanzania has been relatively successful in maintaining peace and stability in comparison with other neighbouring countries in the African region. 'Utu', a Bantu philosophical concept, should be paid attention to in a relationship that has reduced violence. The 'utu' concept is popular within the Swahili culture of Tanzania which encompasses dimensions of social capital such as trust, group membership, everyday sociability, respect, helping others and asking for help and demonstrating love and compassion towards other members of the community.

There have been fewer studies about the influence of sociocultural activities on homicide in low-income countries. The association between adherence to the traditional social and religious values and homicide deaths in Tanzania is worth examining.

The objective of this study was to examine the potential contributions of sociocultural activities to reduce risks of death by homicide, regardless of the status of conventional risk factors in Dar es Salaam, Tanzania. Demographic and sociocultural characteristics by the type of homicide were examined.

\section{METHODS}

\section{Study design}

A case control study was conducted. The Strengthening the Reporting of Observational Studies in Epidemiology (STROBE) statement ${ }^{18}$ was applied to verify adequate reporting.

\section{Setting}

Dar es Salaam is the largest and most prosperous city in Tanzania with a population of 2.5 million as of $2005 .{ }^{19}$ The Tanzanian government's definition of the poverty line for 20002001 was 7253 Tanzanian shillings per capita per 28 days. Given this, $28.7 \%, 15.8 \%$ and $14.3 \%$ of the city were classified as low, middle and upper-middle economy areas, respectively.

In Tanzania, medicolegal autopsies are compulsory in cases of death due to non-natural causes. In the period between June and December 2005, a total of 248 deaths by homicide in Dar es Salaam region, as defined by the International Classification of Diseases (ICD)-10 codes X85-Y09, were confirmed after medical and legal investigations by the Muhimbili National Hospital Mortuary. ICD-10 codes X85-Y09 define unnatural death by homicide as those due to injuries inflicted by another person with intent to injure or kill, by any means, excluding deaths as a result of war and legal interventions.

\section{Participants}

The sample size needed to compare the prevalence of risk factors between cases $(30 \%)$ and controls $(15 \%)$ with significance level 0.05 and power 0.80 were 92 for cases and 184 for controls.

The families of randomly selected 108 cases among 248 victims were approached in order to include 92 cases under the estimated exclusion rate of 15\%. Finally 102 (94.4\%) families of the victims agreed to participate in this study. The reasons for refusals were 'lack of time to participate', 'being in tears mourning the loss of the beloved ones', and not possible to find the victims' family/household. The informed consent was provided by one representative member from each family, who then participated in the interview between 1 June and 31 December 2005. Two experienced interviewers from the Muhimbili University of Health and Allied Sciences conducted interviews. Among 102 families, 12 did not complete all the procedures of the interview, because of the inability to give answers regarding the victims or their refusal to complete the interview. From the remaining 90 cases, all variables for the analysis were validly collected and used for the analysis.

The authors conducted a sampling of a control group, by matching the controls with victims by sex and 5-year age group. Two controls were selected per case. With the cooperation of the National Bureau of Statistics, 220 census enumeration areas each consisting of about 100 families were randomly chosen from 60 city wards of the Dar es Salaam region. Control households were randomly selected from a hand-drawn map of the enumeration area, showing households, streets, roads, rivers and others. A starting point was selected by random selection of a street from the street directory of a given enumeration area. Six interviewers with experience of the National Census data collection from the Tanzania Bureau of Statistics visited selected households in March 2006. They asked if any of its family members matched the victim by age and sex. If a match was found, he/she was asked to participate in the study. If there was no match, or the matching individual refused to participate, then the next nearest household was visited. Finally, 204 controls matching with 102 cases were visited and interviewed. Seven more female control subjects, matching cases by sex and 5 year age group, were added to ensure a sufficient number of female subjects for meaningful analysis. From a total of 211 controls, variables for the analysis were validly collected and used for the analysis.

Face-to-face interviews were conducted with both groups in Swahili using the same structured questionnaire. Employed interviewers were experienced researchers and counsellors. They participated in specifically organised 1-day training for the present study. One of the authors supervised interviewers prior to conducting the interview to ensure correctness of the information to minimise any potential effect of social desirability bias on sensitive questions.

\section{Variables}

Demographic information of the victims such as date of death, cause of death and place of residence were collected through a surveillance questionnaire, which was described previously by Outwater et al. ${ }^{5}$

The household questionnaire survey was constructed based on the guidelines for Conducting Community Surveys on Injuries and Violence ${ }^{20}$ and included questions regarding the victim's educational status, occupation, religion, duration of residence in Dar es Salaam, family structure and home ownership. Participants were also asked about drinking and hard drug (cocaine and heroin) use and feeling about the safety of the neighbourhood during day and night, as well as reports of violence in the neighbourhood. The questions included information regarding religious service attendance as an indicator of faith activities and sociocultural activities.

Sociocultural activities operationalise the concept of 'utu' and include social items: (1) being a member of a community group/ organisation, (2) attending family funerals, (3) helping others with problems/needs, (4) visiting patients and (5) demonstrated love and compassion towards others, and helped others with problems/needs. These five items of sociocultural activities were elaborated by the authors with various research experiences in Bantu and Swahili society and recommendations by the 
anthropological and sociological specialists of the study area. Individual sociocultural activities score was calculated as a sum of 'yes' answer to the questions; five points is a full score.

\section{Statistical analysis}

After demonstrating frequency distribution of study participants by characteristics, bivariate analysis was performed. Age, number of years of residence in Dar es Salaam and the sociocultural activities score of the victims and the control group were compared. The characteristics of the homicide victims by type of deaths (ie, assault or mob violence) were examined. Conditional logistic regression analysis was performed for 90 homicide victims and 211 controls keeping victims of homicide as the dependent variable. A variable of place of residence was included to adjust the influence of a difference in economic levels of the place of residence.

The statistical analysis was performed using SPSS 19.0, and $\alpha$ level 0.05 was considered statistically significant.

Table 1 Sociodemographic characteristics of the study subjects: homicide victims and controls

\begin{tabular}{|c|c|c|c|c|c|}
\hline & \multicolumn{2}{|c|}{$\begin{array}{l}\text { Case } \\
(\mathrm{n}=90)\end{array}$} & \multicolumn{2}{|c|}{$\begin{array}{l}\text { Control } \\
(n=211)\end{array}$} & \multirow[b]{2}{*}{ p Values } \\
\hline & $\mathbf{n}$ & $\%$ & $\mathbf{n}$ & $\%$ & \\
\hline Age $(\text { mean } \pm S D)^{*}$ & \multicolumn{2}{|c|}{$32.4 \pm 10.8$} & \multicolumn{2}{|c|}{$32.1 \pm 10.4$} & 0.804 \\
\hline \multicolumn{6}{|l|}{ Sex } \\
\hline Male & 83 & 92.2 & 193 & 91.5 & 0.828 \\
\hline Female & 7 & 7.8 & 18 & 8.5 & \\
\hline \multicolumn{6}{|l|}{ Place of residence } \\
\hline Lower economy area & 31 & 34.4 & 83 & 39.3 & 0.421 \\
\hline Middle economy area & 20 & 22.2 & 34 & 16.1 & \\
\hline Upper-middle economy area & 39 & 43.3 & 94 & 44.5 & \\
\hline \multicolumn{6}{|l|}{ Educational status } \\
\hline $\begin{array}{l}\text { No education/did not complete } \\
\text { elementary school }\end{array}$ & 15 & 16.7 & 7 & 3.3 & $<0.001$ \\
\hline Elementary school completed & 67 & 74.4 & 135 & 64.0 & \\
\hline Secondary school completed/university & 8 & 8.9 & 69 & 32.7 & \\
\hline \multicolumn{6}{|l|}{ Occupation } \\
\hline Unemployed/retired & 27 & 30.0 & 5 & 2.4 & $<0.001$ \\
\hline Unskilled labour & 47 & 52.2 & 116 & 55.0 & \\
\hline Professional/skilled labour & 11 & 12.2 & 51 & 24.2 & \\
\hline Others & 5 & 5.6 & 39 & 18.5 & \\
\hline \multicolumn{6}{|l|}{ Religion } \\
\hline Christian & 42 & 46.7 & 90 & 42.7 & 0.521 \\
\hline Muslim & 48 & 53.3 & 121 & 57.3 & \\
\hline \multicolumn{6}{|l|}{ Duration of residence in Dar es Salaam } \\
\hline Since birth & 32 & 35.6 & 93 & 44.1 & 0.003 \\
\hline Came as a child & 15 & 16.7 & 43 & 20.4 & \\
\hline Came as an adult & 38 & 42.2 & 75 & 35.5 & \\
\hline Just visiting & 5 & 5.6 & 0 & 0.0 & \\
\hline \multicolumn{6}{|l|}{ Family structure } \\
\hline Alone & 21 & 23.3 & 9 & 4.3 & $<0.001$ \\
\hline With other(s) & 69 & 76.7 & 202 & 95.7 & \\
\hline \multicolumn{6}{|l|}{ Ownership of house } \\
\hline Own home & 13 & 14.4 & 28 & 13.3 & 0.016 \\
\hline Rental home (private and government) & 41 & 45.6 & 92 & 43.6 & \\
\hline Family's home & 32 & 35.6 & 91 & 43.1 & \\
\hline Homeless & 4 & 4.4 & 0 & 0.0 & \\
\hline
\end{tabular}

\section{Ethical clearance}

This study was approved by the Ethical Committees of Muhimbili University of Health and Allied Sciences, National Institute for Medical Research of Tanzania, and Tanzania Commission for Science and Technology. Prior to the interviews, all interviewees gave their written informed consent after reading and understanding the study objectives, confidentiality and ethical considerations, and assurance regarding the voluntary nature of participation.

\section{RESULTS}

The demographic data of the cases (90 homicide victims) and the controls ( 211 controls) are summarised in table 1 . The type of violence responsible for death consisted of mob violence in 53 cases $(58.9 \%)$, assault in 32 cases $(35.6 \%)$ and not identified in the remaining 5 cases $(5.5 \%)$. Among the cases, seven $(7.8 \%)$ were women (six assault cases and one mob victim). The percentage of male victims among the victims of mob violence $(98.1 \%)$ was higher than that among assault victims $(81.3 \%)\left(\chi^{2}\right.$ test, $\mathrm{p}=0.010)$. The percentage of victims who had lived in Dar es Salaam since birth among the mob victims $(47.2 \%)$ was higher than that among the assault victims $(18.8 \%)\left(\chi^{2}\right.$ test, $\mathrm{p}=0.003)$. The percentages of victims who reported a feeling of neighbourhood safety during daytime and night-time among the mob victims $(94.3 \%, 86.8 \%)$ were higher than those among the assault victims $(75.0 \%, 68.8 \%)\left(\chi^{2}\right.$ test, $\left.p=0.009, p=0.043\right)$. The percentage of victims who reported no violence in the neighbourhood among the mob victims (84.9\%) was higher than that among the assault victims $(65.6 \%)\left(\chi^{2}\right.$ test, $\left.\mathrm{p}=0.037\right)$. Table 2 shows alcohol and hard drug use as well as social relationships of the victims and the subjective feeling regarding neighbourhood safety of the interviewees. There were statistically significant differences between the victims and controls with regard to heavy alcohol consumption and hard drug use, frequency of attending a place of worship, attendance to family funerals, helping others with problems or needs, demonstrating love and compassion towards others and sociocultural activities score.

The results of the conditional logistic regression analysis (table 3) indicate that being employed, having a higher level of education, longer period of residence in Dar es Salaam, living with another person, not drinking frequently and attending a place of worship more than once a week were associated with not becoming a victim of homicide.

\section{DISCUSSION}

The results of a matched case control study using the reports of medicolegal autopsies and systematically performed face-to-face interviews indicated that frequent religious service attendance, having a long period of residence in the same place and living with another person were shown to be factors that reduce risks of becoming a victim of homicide. Contribution of other factors, being employed, having a high level of education and infrequent use of alcohol were also confirmed as factors associated with not being a victim of homicide.

The incidence of homicide is likely to be higher in areas of poor economic conditions and low social cohesion. ${ }^{21}$ A potential selection bias due to non-matching of the location of residence did not influence the validity of the major results of this study, because the results of the conditional logistic regression analysis did not show an influence of location of residence to homicide deaths. A potential bias is related to a reporting bias because controls gave self-reports, while this was obviously 
Table 2 Alcohol and hard drug use, subjective feeling of neighbourhood safety, attendance at places of worship and social relationships of the study participants: homicide victims and controls

\begin{tabular}{|c|c|c|c|c|c|}
\hline & \multicolumn{2}{|c|}{$\begin{array}{l}\text { Case } \\
(\mathrm{n}=90)\end{array}$} & \multicolumn{2}{|c|}{$\begin{array}{l}\text { Control } \\
(n=211)\end{array}$} & \multirow{2}{*}{$\begin{array}{l}p \\
\text { Values }\end{array}$} \\
\hline & $\mathrm{n}$ & $\%$ & $\mathbf{n}$ & $\%$ & \\
\hline \multicolumn{6}{|l|}{ Frequent heavy drinking } \\
\hline Yes & 30 & 33.3 & 10 & 4.7 & \multirow[t]{2}{*}{$<0.001$} \\
\hline No & 60 & 66.7 & 201 & 95.3 & \\
\hline \multicolumn{6}{|l|}{ Hard drug use } \\
\hline Yes & 20 & 22.2 & 4 & 1.9 & \multirow[t]{2}{*}{$<0.001$} \\
\hline No & 70 & 77.8 & 207 & 98.1 & \\
\hline \multicolumn{6}{|c|}{ Feeling of neighbourhood safety during daytime } \\
\hline Unsafe & 10 & 11.1 & 19 & 9.0 & \multirow[t]{3}{*}{0.258} \\
\hline Safe & 79 & 87.8 & 192 & 90.0 & \\
\hline Don't know & 1 & 1.1 & 0 & 0.0 & \\
\hline \multicolumn{6}{|c|}{ Feeling of neighbourhood safety during night-time } \\
\hline Unsafe & 19 & 21.1 & 51 & 24.2 & \multirow[t]{2}{*}{0.565} \\
\hline Safe & 71 & 78.9 & 160 & 75.8 & \\
\hline \multicolumn{6}{|l|}{ Reported violence in the neighbourhood } \\
\hline Yes & 19 & 21.1 & 56 & 26.5 & \multirow[t]{2}{*}{0.319} \\
\hline No & 71 & 78.9 & 155 & 73.5 & \\
\hline \multicolumn{6}{|c|}{ Frequency of attendance to religious services } \\
\hline Never attended & 41 & 45.6 & 30 & 14.2 & \multirow[t]{3}{*}{$<0.001$} \\
\hline More than once a year & 25 & 27.8 & 40 & 19.0 & \\
\hline More than once a week & 24 & 26.7 & 141 & 66.8 & \\
\hline \multicolumn{6}{|c|}{ Membership of any community group/organisation } \\
\hline No & 61 & 67.8 & 154 & 73.0 & \multirow[t]{2}{*}{0.360} \\
\hline Yes & 29 & 32.2 & 57 & 27.0 & \\
\hline \multicolumn{6}{|l|}{ Attending family funerals } \\
\hline No & 7 & 7.8 & 3 & 1.4 & \multirow[t]{2}{*}{0.009} \\
\hline Yes & 83 & 92.2 & 208 & 98.6 & \\
\hline \multicolumn{6}{|l|}{ Helping others with problems/needs } \\
\hline No & 17 & 18.9 & 15 & 7.1 & \multirow[t]{2}{*}{0.002} \\
\hline Yes & 73 & 81.1 & 196 & 92.9 & \\
\hline \multicolumn{6}{|l|}{ Visiting patients } \\
\hline No & 20 & 22.2 & 32 & 15.2 & \multirow[t]{2}{*}{0.138} \\
\hline Yes & 70 & 77.8 & 179 & 84.8 & \\
\hline \multicolumn{6}{|c|}{ Demonstrating love and compassion towards others } \\
\hline No & 4 & 4.4 & 1 & 0.5 & \multirow[t]{2}{*}{0.029} \\
\hline Yes & 86 & 95.6 & 210 & 99.5 & \\
\hline $\begin{array}{l}\text { Individual sociocultural activities score } \\
(\operatorname{mean} \pm \mathrm{SD})^{*}\end{array}$ & \multicolumn{2}{|c|}{$3.8 \pm 1.3$} & \multicolumn{2}{|c|}{$4.0 \pm 0.7$} & 0.039 \\
\hline $\begin{array}{l}\chi^{2} \text { test was performed for all variables } \\
\text { activities score. } \\
{ }^{*} \text { Individual sociocultural activities score: } \\
\text { were shown. }\end{array}$ & & eption of & & dual soci & $\begin{array}{l}\text { ocultural } \\
\text { nd SD }\end{array}$ \\
\hline
\end{tabular}

impossible for the murder victims. However, strong relationships shown between cases and controls in terms of key variables revealed little effect of this potential bias.

The frequency of attendance at a place of worship contributed towards reducing the risk of death by homicide. Spiritual care, religiosity and worship practice are important in preventing youth violence. ${ }^{22}$ Places of worship provide appropriate opportunities for orientation and promotion of health for children and family. ${ }^{23}$ Religious commitment and spiritual practice may have positive effects on reducing the risk of becoming a victim of violence by mitigating disadvantaged conditions, including lower levels of educational attainment and poor socioeconomic status. The attendance at a place of worship, regardless of the religion, and also building and maintaining close and intimate relationships with family and relatives are factors strengthening resilience against violence.

Our results from Tanzania suggested that living in the same place for many years and establishing close and intimate relationships within the neighbourhood could contribute to alleviation of social inequality and increase social connectedness. Collective efficacy as social cohesion will help reduce violence by increasing neighbourhood security and residential stability. ${ }^{21}$ This study demonstrated the important role of 'utu' as a way of life in protecting individuals and communities from violence. Protective factors against homicide such as social connectedness, residential stability, participation in worship services and improved social status are more likely to flourish in neighbourhoods with a strong sense of 'utu'.

This study highlighted the importance of promoting human relationships in protecting individuals from becoming involved in violence. Living with other people is a factor in preventing deaths due to homicide. Appropriate family cohesion promotes health by preventing drug use among young people, ${ }^{24}$ and acting as a buffer against deleterious influences on lifestyle. ${ }^{25}$ Supervision by parents and community neighbours is associated with externalising behaviours among youth. ${ }^{26}$ Connectedness with and moderate monitoring by parents and other adults prevented youth violence. $^{22} 27$ The items regarding relationships with relatives and others, such as attending family funerals, helping others with problems/needs and demonstrating love and compassion towards others reduce the risk of becoming victims of homicide. Strengthening of relationships with family and kinship could therefore represent a possible intervention for reducing the risk of homicide deaths.

Neighbourhood environment and living conditions, including safety, are factors in increasing the risks of homicide deaths. ${ }^{28}$ Poverty, income inequality, socioeconomic disparity among neighbourhoods and disadvantaged conditions are known to increase the rates of homicide death. ${ }^{29} 30$ The pattern of mortality varies according to the social conditions of the communities. $^{31}$ Our results showed that family structure and neighbourhood safety was related with becoming victims of mob violence. Safe neighbourhoods in Dar es Salaam work cohesively for community safety.

Most victims of mob violence in Tanzania were suspected thieves and were predominantly young men. ${ }^{5}$ In Nigeria, most mob violence was due to political reasons. ${ }^{32}$ In Ghana, mob violence predominantly targeted elderly women who were suspected of practicing witchcraft. ${ }^{33}$ Further studies should examine the interplay of demographic, sociocultural, environmental and economical factors related to mob violence victimisation and perpetration across countries in the African region.

Community networks and family relations are often presumed to be strong in African cultures. However, urban life in Africa is undergoing dynamic changes in terms of family structure and community networks. Tanzania is no exception in that; at least in large cities, such as Dar es Salaam, there has been an increase in nuclear families, ${ }^{34}$ weakening of family ties and reduced communal efficacy. ${ }^{35}$ Moving to Dar es Salaam as an adult may be a positive contribution to creating a stable living condition due to the opportunity of employment, but it may also negatively affect intimate human relationships with family, neighbours and community. Further studies are required to analyse a relationship between the current trend of movement to urban areas and risk of violence, including the background conditions of mob violence. 
Table 3 Factors associated with becoming a victim of homicide (90 homicide victims and 211 controls)

\begin{tabular}{|c|c|c|c|c|c|c|}
\hline & OR & $95 \%(\mathrm{Cl})$ & p Values & AOR & $95 \%(\mathrm{Cl})$ & p Values \\
\hline \multicolumn{7}{|l|}{ Place of residence } \\
\hline Lower economy area & 1 & & & 1 & & \\
\hline Middle economy area & 1.575 & 0.790 to 3.138 & 0.197 & 1.380 & 0.876 to 6.040 & 0.091 \\
\hline Upper-middle economy area & 1.111 & 0.637 to 1.938 & 0.711 & 2.300 & 0.586 to 3.251 & 0.461 \\
\hline \multicolumn{7}{|l|}{ Occupation } \\
\hline Unemployed/retired & 1 & & & 1 & & \\
\hline Unskilled labour & 0.075 & 0.027 to 0.207 & $<0.001$ & 0.039 & 0.010 to 0.148 & $<0.001$ \\
\hline Professional/skilled labour & 0.040 & 0.013 to 0.127 & $<0.001$ & 0.072 & 0.015 to 0.343 & 0.001 \\
\hline Others & 0.024 & 0.006 to 0.090 & $<0.001$ & 0.045 & 0.008 to 0.250 & $<0.001$ \\
\hline \multicolumn{7}{|l|}{ Educational status } \\
\hline No education/did not complete elementary school & 1 & & & 1 & & \\
\hline Elementary school completed & 0.232 & 0.090 to 0.595 & 0.002 & 0.171 & 0.043 to 0.688 & 0.013 \\
\hline Secondary school completed & 0.054 & 0.017 to 0.172 & $<0.001$ & 0.021 & 0.003 to 0.133 & $<0.001$ \\
\hline \multicolumn{7}{|l|}{ Duration of residence in Dar es Salaam } \\
\hline Since birth & 1 & & & 1 & & \\
\hline Came as a child & 1.014 & 0.497 to 2.066 & 0.970 & 1.138 & 0.376 to 3.447 & 0.819 \\
\hline Came as an adult & 1.472 & 0.841 to 2.578 & 0.176 & 3.952 & 1.430 to 10.920 & 0.008 \\
\hline Just visiting & - & - & & - & - & \\
\hline \multicolumn{7}{|l|}{ Family structure } \\
\hline Alone & 1 & & & 1 & & \\
\hline With somebody(s) & 0.146 & 0.064 to 0.335 & $<0.001$ & 0.070 & 0.017 to 0.284 & $<0.001$ \\
\hline \multicolumn{7}{|l|}{ Ownership of house } \\
\hline Own home & 1 & & & 1 & & \\
\hline Rental home (private and government) & 0.960 & 0.452 to 2.040 & 0.915 & 0.177 & 0.054 to 0.576 & 0.004 \\
\hline Family's home & 0.757 & 0.350 to 1.638 & 0.480 & 0.408 & 0.123 to 1.353 & 0.143 \\
\hline Homeless & - & - & & - & - & \\
\hline \multicolumn{7}{|l|}{ Frequent alcohol drinking } \\
\hline Yes & 1 & & & 1 & & \\
\hline No & 0.100 & 0.046 to 0.215 & $<0.001$ & 0.152 & 0.049 to 0.472 & 0.001 \\
\hline \multicolumn{7}{|l|}{ Frequency of attendance to religious services } \\
\hline Never attended & 1 & & & 1 & & \\
\hline More than once a year & 0.457 & 0.230 to 0.909 & 0.026 & 0.663 & 0.253 to 1.738 & 0.405 \\
\hline More than once a week & 0.125 & 0.066 to 0.236 & $<0.001$ & 0.123 & 0.046 to 0.329 & $<0.001$ \\
\hline
\end{tabular}

\section{CONCLUSIONS}

The results of this study indicated an association of frequent participation in religious service, living in the same place for a long time, living with someone, occupation and education, in preventing homicide deaths in a low-income setting. Policy makers and public leaders should be aware of the importance of existing non-structural community resources and social cohesive networks to strengthen individual and community resilience against violence in addition to the overall goal of improving socioeconomic equity and security of communities.

\section{What is already known on this subject}

- Being employed, having a high level of education and infrequent use of alcohol are factors that reduce the risk of death by homicide.

- Homicide rates are higher in Tanzania, particularly in urban settings, compared with the world average.

\section{What this study adds}

- Sociocultural activities adherent to traditional social and religious values, such as frequent religious service attendance, contribute towards reducing the risk of death by homicide in Dar es Salaam.

- Living in the same place for a long time and living with another person are factors that contribute towards reducing the risk of death by homicide.

- More than half of the homicide deaths in Dar es Salaam are due to mob violence. A greater proportion of victims of mob violence felt neighbourhood safety than the victims of assault.

Acknowledgements This research is part of a PhD programme for the first author funded by the Government of Japan, Ministry of Education, Culture, Sports, Science and Technology. 
Contributors SMK was responsible for data analysis and wrote the manuscript. $\mathrm{MO}$ contributed to conceptualisation of the study and writing a draft of the manuscript. AO prepared a draft of the study proposal, was responsible for data collection and contributed to the writing of the manuscript. KS and MK contributed to data analysis and interpretations and revisions of the draft manuscript. TT supervised conceptualisation of the analytical framework, data analysis and writing of the manuscript. All authors read and approved the final manuscript.

Funding This work was supported by Ruth L Kirschstein National Research Service Award, NIH NINR 1 F31 NR008809-01A19/2002-8/2004.

\section{Competing interests None.}

Patient consent Obtained.

Ethics approval Ethical Committees of Muhimbili University of Health and Allied Sciences, National Institute for Medical Research of Tanzania, and Tanzania Commission for Science and Technology.

Provenance and peer review Not commissioned; externally peer reviewed.

Open Access This is an Open Access article distributed in accordance with the Creative Commons Attribution Non Commercial (CC BY-NC 3.0) license, which permits others to distribute, remix, adapt, build upon this work non-commercially, and license their derivative works on different terms, provided the original work is properly cited and the use is non-commercial. See: http://creativecommons.org/ licenses/by-nc/3.0/

\section{REFERENCES}

1 World Health Organization. The global burden of disease 2008 update. Geneva: World Health Organization, 2011. http://apps.who.int/ghodata/ (accessed 28 Oct 2011).

2 World Health Organization. World report on violence and health. Geneva: World Health Organization, 2002.

3 Krug EG, Mercy JA, Dahlberg LL, et al. he world report on violence and health. Lancet 2002;360:1083-8.

4 Lewis CG. General data dissemination project (GDSS II): The World Bank, Technical assistance mission to Tanzania, Justice and security module. http://siteresources. worldbank.org/SCBEXTERNAL/Resources/Report_Justice_Tanzania_Lewis_T1.pdf (accessed 6 Dec 2011).

5 Outwater AH, Campbell JC, Mgaya E, et al. Homicide death in Dar es Salaam, Tanzania 2005. Int J Inj Contr Saf Promot 2008:15:243-52.

6 Pridemore WA. What we know about social structure and homicide: a review of the theoretical and empirical literature. Violence Vict 2002:17:127-56.

7 Louw A, Robertshaw R, Mtani A. Dar es Salaam: victim surveys as a basis for city safety strategies. Afr Secur Rev 2001;10:60-74.

8 Galea S, Ahern J. Distribution of education and population health: an ecological analysis of New York City neighborhoods. Am J Public Health 2005;95:2198-205.

9 Muazzam S, Nasrullah M. Macro determinants of cause-specific injury mortality in the OECD countries: an exploration of the importance of GDP and unemployment. J Community Health 2011:36:574-82.

10 Kposowa A, Singh G, Breault K. The effects of marital status and social isolation on adult male homicides in the United State: Evidence from the National Longitudinal Mortality Study. J Quant Criminol 1994;10:277-89.

11 Pridemore WA. Weekend effects on binge drinking and homicide: the social connection between alcohol and violence in Russia. Addiction 2004;99:1034-41.

12 Ribeiro M, Dunn J, Sesso R, et al. Causes of death among crack cocaine users. Rev Bras Psiquiatr 2006;28:196-202

13 Pardini $D A$, Loeber $R$, Farrington $D P$, et al. Identifiying direct protective factors for nonviolence. Am J Prev Med 2012:43(2 Suppl 1):S28-40.
14 Salas-Wright $\mathrm{CP}$, Vaughn MG, Hodge DR, et al. Religiosity profiles of American youths in relation to substance use, violence, and delinquency. J Youth Adolesc 2012:3:3

15 El Hajj T, Afifi RA, Khawaja M, et al. Violence and social capital among young men in Beirut. Inj Prev 2011:17:401-6.

16 Seedat M, Van Niekerk $A$, Jewkes $R$, et al. Violence and injuries in South Africa: prioritising and agenda for prevention. Lancet 2009;374:1011-22.

17 World Health Organization. Global health risks: mortality and burden of disease attributable to selected major risks. Geneva: World Health Organization, 2009.

18 STROBE Statement: Strengthening the reporting of observational studies in epidemiology. http://www.strobe-statement.org/ (accessed 6 Dec 2011).

19 Dar es Salaam City Council. Dar es Salaam city profile. Dar es Salaam: Dar es Salaam City Council, 2004.

20 McGee K, Sethi D, Peden M, et al. Guidelines for conducting community surveys and violence. Inj Control Saf Promot 2004;11:303-6.

21 Sampson RJ, Raudenbush SW, Earls F. Neighborhoods and violent crime: a multilevel study of collective efficacy. Science 1997;277:918-24.

22 Resnick MD, Ireland M, Borowsky I. Youth violence perpetration: what protects? What predicts? Findings from the National Longitudinal Study of Adolescent Health. J Adolesc Health 2004;35:424 e1-10.

23 Maynard MJ, Baker G, Rawlins E, et al. Developing obesity prevention interventions among minority ethnic children in schools and places of worship: the DEAL (DiEt and Active Living) study. BMC Public Health 2009:9:480.

24 Wagner KD, Ritt-Olson A, Chou CP, et al. Associations between family structure, family functioning, and substance use among Hispanic/Latino adolescents. Psychol Addict Behav 2010;24:98-108.

25 Turagabeci AR, Nakamura K, Kizuki M, et al. Family structure and health, how companionship acts as a buffer against ill health. Health Qual Life Outcomes 2007:5:61.

26 Beyers JM, Bates JE, Pettit GS, et al. Neighborhood structure, parenting processes, and the development of youths' externalizing behaviors: a multilevel analysis. Am J Community Psychol 2003:31:35-53.

27 McDaniel DD. Risk and protective factors associated with gang affiliation among high-risk youth: a public health approach. Inj Prev 2012. (E-publication ahead of print)

28 Cubbin C, LeClere FB, Smith GS. Socioeconomic status and injury mortality: individual and neighbourhood determinants. I Epidemiol Community Health 2000;54:517-24

29 Krueger PM, Bond Huie SA, Rogers RG, et al. Neighbourhoods and homicide mortality: an analysis of race/ethnic differences. J Epidemiol Community Health 2004:58:223-30.

30 Szwarcwald $\mathrm{CL}$, Bastos Fl, Viacava F, et al. Income inequality and homicide rates in Rio de Janeiro, Brazil. Am J Public Health 1999:89:845-50.

31 Groenewald P, Bradshaw D, Daniels J, et al. Local-level mortality surveillance in resource-limited settings: a case study of Cape Town highlights disparities in health. Bull World Health Organ 2010;88:444-51.

32 Seleye-Fubar D, Etebu EN, Athanasius B. Pathology of deaths from mob action in the Niger Delta Region of Nigeria. A study of 38 consecutive autopsies. Niger J Med 2011;20:241-4.

33 Adinkrah $\mathrm{M}$. Witchcraft accusation and female homicide victimization in contemporary Ghana. Violence Against Women 2004;20:325-56.

34 Tanzania: Household Budget Survey 2007. Tanzania mainland. Dar es Salaam: National Bureau of Statistics, 2008.

35 Kilonzo GP, Simmons N. Development of mental health services in Tanzania: a reappraisal for the future. Soc Sci Med 1998;47:419-28.

Jake Olivier brought my attention to a new Elsevier journal, J of Transport and Health affiliated with the Transport and Health Study Group in the UK. One stated policy objective of the journal is "To promote a more balanced approach to cycle safety and oppose cycle helmet legislation". To help the opposition, the editorial board includes Chris Rissel and Malcolm Wardlaw, both outspoken opponents of helmet laws. It seems surprising that a supposedly reputable scientific publisher would produce a journal that exists in part to support a position that is still very much under scrutiny, serving in effect as the mouthpiece of the anti-helmet movement.

http://www.transportandhealth.org.uk/ 